\title{
Functional perfectionism and healthy behaviors: the longitudinal relationships between the dimensions of perfectionism, nutrition behavior, and physical activity moderated by gender
}

\author{
Aleksandra Luszczynska ${ }^{1 \cdot A, B, C, D, E, F, G}$, Karolina Zarychta ${ }^{2 \cdot B, C, D, E}$, Karolina Horodyska ${ }^{2 \cdot B, D, E, F}$, \\ Natalia Liszewska ${ }^{2 \cdot B, D, E, F}$, Anna Gancarczyk ${ }^{2 \cdot B, D, E, F}$, Katarzyna Czekierda ${ }^{2 \cdot B, D, E, F}$ \\ 1: Trauma, Health, \& Hazards Center, University of Colorado, Colorado Springs, USA \\ 2: University of Social Sciences and Humanities, Department in Wroclaw, Poland
}

BACKGROUND

This study investigated the relationships between global perfectionism (its functional and dysfunctional aspects) and three types of health behaviors: fruit and vegetable intake (FVI), consumption of sweet and salty snacks, and physical activity. It was hypothesized that indices of functional perfectionism would predict engaging in healthy behavior, with gender moderating these associations.

PARTICIPANTS AND PROCEDURES

Data were collected among 845 adolescents $(59.20 \%$ girls $)$ aged 13 to 20 years old $(M=16.52, S D=0.92)$. At the baseline, participants filled out the Frost Multidimensional Perfectionism Scale and measures of nutrition behavior and physical activity. The measurement of nutrition behavior and physical activity was repeated at 12-month follow-up.

\section{RESULTS}

The moderator analysis indicated that FVI as well as consumption of sweet and salty snacks measured at 12-month follow-up were explained by functional global perfection- ism (Organization and Personal Standards dimensions), but this effect was stronger among girls. Physical activity measured at 12-month follow-up was explained by functional perfectionism (Organization and Personal Standards dimensions), but this effect was stronger among boys. The effects were found after controlling for respective behaviors assessed at the baseline. Dysfunctional dimensions of global perfectionism (Concern over Mistakes, Parental Expectations, Parental Criticism, Doubts about Actions) were unrelated to indices of behavior at follow-up.

\section{CONCLUSIONS}

Functional global perfectionism may represent an individual resource variable, facilitating uptake and maintenance of healthy diet and physical activity, and therefore foster prevention of obesity among adolescents.

\section{KEY WORDS}

adolescence; perfectionism; obesity; diet; physical activity; gender

CORRESPONDing AUthor - Prof. Aleksandra Luszczynska, Trauma, Health, \& Hazards Center, University of Colorado,

1861 Austin Bluffs Pkwy, Colorado Springs, CO 80918, USA, e-mail: aluszczy@uccs.edu

AUthors' CONTRIBUtion - A: Study design - B: Data collection - C: Statistical analysis - D: Data interpretation .

E: Manuscript preparation · F: Literature search · G: Funds collection

TO CITE this ARTICle - Luszczynska, A., Zarychta, K., Horodyska, K., Liszewska, N., Gancarczyk, A., \& Czekierda, K.

(2015). Functional perfectionism and healthy behaviors: the longitudinal relationships between the dimensions

of perfectionism, nutrition behavior, and physical activity moderated by gender. Current Issues in Personality

Psychology, 3(2), 84-93.

RECEIVED 18.04.2015 · REVIEWED 12.05.2015 • ACCEPTED 22.05.2015 · PUBLISHED 08.06.2015 


\section{BACKGROUND}

Adolescence is a period of increased risk of unfavorable body weight changes associated with the consumption of energy-dense snacks, such as sweets, and processed salty foods (Piernas \& Popkin, 2010). The World Health Organization (WHO, 2004) states that adolescents constitute a group of particular concern: more efforts should be devoted to identifying effective interventions to change an unhealthy diet of a child/adolescent into a healthy one. Healthy nutrition among adolescents is of particular relevance: poor nutrition behaviors are closely related to adolescent obesity, which in turn has a number of adverse consequences for physical and mental health, in both the short term (for obese adolescents) and long term (for adults who were obese in childhood), including increased risk for premature mortality (Reilly \& Kelly, 2011). Thus investigating psychosocial determinants of nutrition behaviors in adolescence is among the priorities of health psychology.

Physical activity (PA) is one of the crucial determinants of the key non-communicable diseases, including diabetes, cardiovascular diseases and cancer (Hallal, Victora, Azevedo, \& Wells, 2006). However, the health benefits of physical activity depend on its intensity and duration (Pate et al., 2002; Warburton, Nicol, \& Bredin, 2006), with more pronounced health benefits being associated with moderate-to-vigorous physical activity (MVPA). Longitudinal research assessing physical activity from early to late adolescence has indicated a decline in physical activity (e.g., Nelson, NeumarkSztainer, Hannan, Sirard, \& Story, 2006). Physical activity levels tend to remain stable from early to middle adolescence, but a substantial reduction in time spent on exercise is observed in late adolescence (Nelson et al., 2006). The observed decline in physical activity is especially marked among girls (Pate et al., 2002). Thus the determinants of physical activity among adolescents warrant further investigation.

The construct of perfectionism has a long history in personality and clinical psychology. For over three decades research has stressed its multidimensional character (Frost, Marten, Lahart, \& Rosenblate, 1990; Stoeber, 1998). For example, one of the early models of perfectionism (Frost et al., 1990) proposes the 6-dimensional approach to perfectionism, including such dimensions as Concern over Mistakes, Personal Standards, Parental Expectations, Parental Criticism, Doubts about Actions, and Organization. One of the most prominent features of perfectionism is setting very high standards for one's own behaviors and goals (Frost et al., 1990). These high standards may be accompanied by tendencies to form excessively critical evaluations of one's own behavior, expressed in concerns about mistakes (Frost et al., 1990). Perfectionists place considerable value on their parents' evaluations and expectations. Finally, they overemphasize the importance of organization and order (Frost et al., 1990). In general, perfectionism is considered to represent a personality trait that plays a relevant role in cognitive, affective and behavioral functioning, and has been long considered a significant determinant of various domains of human functioning (Gotwals, Stoeber, Dunn, \& Stroll, 2012).

The interest in perfectionism is fueled by existing debate and controversy concerning the character of the influence of perfectionism on behavior. The debate focuses on whether perfectionism is a maladaptive disposition (cf. Sherry, Hewitt, Sherry, Flett, \& Graham, 2010) or whether it may also have some adaptive aspects (cf. Stoeber, Uphill, \& Hotham, 2009). A recent systematic review of 31 studies conducted among athletes showed considerable evidence that among young people perfectionistic strivings are predominantly adaptive, occasionally neutral and rarely of maladaptive character (cf. Gotwals et al., 2012). Further, research indicated that the four dimensions of perfectionism referring to evaluation concerns (Concern over Mistakes, Parental Expectations, Parental Criticism and Doubts about Actions) may be related to a variety of problems in an individual's functioning, such as anxiety, insomnia, social phobia, symptoms of anorexia nervosa or symptoms of obsessive-compulsive disorder (for an overview see Stoeber, 1998). In contrast, the remaining two dimensions referring to Organization and Personal Standards are associated with outcomes indicating high functioning and adaptation, such as success orientation (Frost \& Henderson, 1991), and goal commitment (Flett, Sawatzky, \& Hewitt, 1995). Overall, research indicating divergent findings for the dimensions of perfectionism led to establishing two broader categories: one called positive or functional perfectionism, representing strivings encompassing high personal standards and striving for perfection, and another called negative or dysfunctional perfectionism, characterized by concerns over mistakes and failures to meet one's own and others' expectations (Haase, Prapacessis, \& Owens, 2013).

Perfectionism is often defined and measured as a domain-specific construct which is referred to specific actions, domains of functioning, or goal behaviors (cf. Gotwals et al., 2012; Haase et al., 2013). It may be conceptualized and measured in a more general (or global) way (cf. Frost et al., 1990), as the expectations or evaluations referring to a broader range of areas of functioning. In contrast to the domain-specific approach, a general approach to perfectionism provides an opportunity to assess this construct in a parsimonious way, when researchers investigate adaptation of an individual across domains of functioning (cf. Luszczynska, Scholz, \& Schwarzer, 2005).

A number of researchers found that domain-specific indices of functional perfectionism are related to high- 
er levels of physical activity (cf. Gotwals et al., 2012; Longbottom, Grove, \& Dimmock, 2010). Unfortunately, the vast majority of research examining perfectionism - physical activity associations were conducted applying cross-sectional design (cf. Longbottom et al., 2010). Additionally, those associations are less established for general indices of perfectionism.

A myriad of studies have investigated associations between perfectionism and symptoms of eating disorders (for a review see Franco-Paredes, MancillaDiaz, Vazquez-Arevalo, Lopez-Aguilar, \& AlvarezRayon, 2005). Importantly, the functional aspects of perfectionism are often neglected in explaining links between eating disorder symptoms and perfectionism (Franco-Paredes et al., 2005). Further, much less is known about associations between perfectionism and healthy eating behaviors, such as high levels of fruit and vegetable intake or reduced consumption of sweet and salty snacks. To date, studies have tested whether global mixed indices of perfectionism (i.e., accounting for both functional and dysfunctional characteristics of perfectionism) formed negligible associations with nutrition behavior indices such as breakfast consumption (Arata, Battini, Chiorri, \& Masini, 2010) or with its outcomes, such as body mass index and its changes (Stotland \& Larocque, 2005). However, the associations between nutrition behaviors and global functional perfectionism remain unknown.

Research on perfectionism and gender indicated systematic differences between men and women in terms of the average levels of functional and dysfunctional perfectionism (Haase et al., 2013). For example, men showed higher levels of functional perfectionism assessed with a physical-activity domain-specific measure (Haase et al., 2013). Further, gender is an established moderator of the associations between dysfunctional perfectionism and symptoms of eating disorders, with stronger associations found for women (Shanmugam \& Davies, 2015). Unfortunately, the effect of gender in the associations between functional and dysfunctional aspects of global perfectionism and healthy behaviors (such as FVI, sweet and salty snack intake, physical activity) remains unknown.

\section{STUDY AIMS}

The purpose of this study was to investigate associations between the dimensions of global perfectionism, adolescents' gender, and three health behaviors: fruit and vegetable intake, sweet and salty snack intake, and moderate-to-vigorous physical activity. Identifying predictors of long-term changes (i.e., observed over a period of at least 12 months) in healthy behaviors is the key to effective health promotion (Dombrowski et al., 2012). Therefore, our study evaluated the relationships between perfectionism and healthy behaviors using a longitudinal design with a time gap of 12 months between the first and second measurement.

It was hypothesized that compared to the dimensions of dysfunctional perfectionism, the dimensions of functional perfectionism (Organization and Personal standards) measured at $\mathrm{T} 1$ would better predict adolescents health behaviors at 12-month follow-up. We expected that the effects of functional perfectionism on nutrition behaviors may be stronger among girls, whereas the effects of functional perfectionism on moderate-to-vigorous physical activity may be stronger among boys.

\section{PARTICIPANTS AND PROCEDURE}

\section{PARTICIPANTS AND DATA COLLECTION PROCEDURES}

At Time 1 (T1), 845 adolescents (59.20\% girls) aged 13 to 20 years old $(M=16.52, S D=0.92)$ participated in the study. Among participants $0.80 \%$ were underweight, $24.60 \%$ had overweight or obesity, and the remaining $74.60 \%$ had normal body weight, using WHO growth reference charts (De Onis et al., 2007). At Time 2 (T2; 12 months later) 537 (63.60\%) adolescents provided their self-reported data.

The study was conducted in 16 public middle and high schools in Central, Eastern, and South-Western Poland. Participant and parental consent was obtained prior to the data collection. Individuals were informed about the objectives and the procedure of the study. For those who agreed and provided informed consent, personal codes were assigned to secure anonymity and identification across the measurement points. Parents of those younger than 18 years old provided their informed consent. At T1 each participant filled in questionnaires including measures of perfectionism and healthy behaviors. Afterwards, their height and weight were measured individually by experimenters in another room or in the school nurse's office. This procedure was repeated at T2. Experimenters were available for consultations after study completion. Multiple efforts were made to reduce attrition, and at $\mathrm{T} 2$ experimenters returned 3-5 times across a three-week period in order to gain access to participants who were willing to respond but were temporarily absent. Attrition partially related to graduating, changing or dropping out of school by participants. The study was approved by the Institutional Review Board at the first author's university.

\section{MEASURES}

Dimensions of perfectionism, sociodemographic variables, body weight and height were measured 
at T1, whereas three indices of healthy behaviors (MVPA, FVI and sweet and salty snack intake) were measured at T1 and T2.

Dimensions of perfectionism (T1) were measured with six original subscales derived from the 35-item Multidimensional Perfectionism Scale (Frost et al., 1990). The responses were given on a 5 -point scale ranging from 1 (definitely not) to 5 (exactly true).

The Concern over Mistakes scale consists of nine items which reflect negative reactions to mistakes, a tendency to interpret mistakes as equivalent to failure, and a tendency to believe that one will lose the respect of others following failure (e.g., "I should be upset if I make a mistake"). The Parental Expectations scale evaluates the tendency to believe that one's parents set very high goals (e.g., "My parents expected excellence from me"). This scale has five items $(\alpha=.56)$. The Parental Criticism scale (five items; $\alpha=.57$ ) and measures the perception that one's parents are overly critical (e.g., "I never felt like I could meet my parents' standards"). The Doubting of Actions scale consists of three items $(\alpha=.62)$ reflected the extent to which people doubted their ability to accomplish tasks (e.g., "Even when I do something very carefully, I often feel that it is not quite right"). The Organization scale (six items; $\alpha=.71$ ) measures the importance placed on order (e.g. "Organization is very important to me"). The Personal Standards scale (six items; $\alpha=.71$ ) reflects the setting of very high standards for one's own performance and its self-evaluation (e.g., "I expect higher performance in my daily tasks than most people") and addresses high personal standards referring to goal setting (e.g. "I set higher goals than most people").

Body weight and height (T1) were assessed with standard medically approved telescopic height measuring rods and floor scales (scale type: BF-100 or BF-25). Age- and gender-specific body mass index (BMI) percentiles were calculated with the WHO AnthroPlus macro (WHO, 2007), which is software for the global application of the WHO growth reference (De Onis et al., 2007) for children and adolescents. Thus, the BMI indicator of each participant accounts for their age and gender. Body mass index values were coded onto three weight status categories based on $S D$ cut-offs ( 0 - underweight [less than or equal to $2 S D$ ], 1 - normal weight, 2 - overweight or obesity [greater than or equal to $1 S D$ ]) based on the WHO growth reference (De Onis et al., 2007).

Energy-dense foods intake was measured at T1 and T2 with two items, "How many sweet high-energy snacks (e.g., a portion of cookies or candies) do you eat on an average day?" and "How many salty high-energy snacks (e.g., a portion of chips or pretzels) do you eat on an average day?" (cf. Lally, Bartle, \& Wardle, 2011; Luszczynska et al., 2013). The responses were given on a scale ranging from 1 (once per day or less frequently) to 6 (four times or more of- ten). The reliability was moderate $(r=.44$ at $\mathrm{T} 1$ and $r=.47$ at $\mathrm{T} 2$ ).

To assess fruit and vegetable intake (T1 and T2), adolescents answered two questions, adopted from Lally et al. (2011): "How many portions of fresh fruit do you eat on an average day?" and "How many portions of vegetables (fresh, boiled or baked, not fried with fat) do you eat on an average day?". The portion was defined as the amount fitting into a cupped hand. The responses were given on a six-point scale, ranging from 1 (once a week or less) to 6 (four or more times a day). The reliability was moderate $(r=.41$ at $\mathrm{T} 1$ and $r=.42$ at $\mathrm{T} 2)$.

Moderate and vigorous physical activity at $\mathrm{T} 1$ and T2 was assessed using two items from the Godin Leisure-Time Exercise Questionnaire (Godin \& Shephard, 1985). The item example is "Considering a 7-day period (a week), how many times on average do you do the following kinds of exercise for more than 15 minutes during your free time: strenuous exercise (heart beats rapidly), e.g. running, jogging, hockey, football, soccer, basketball, cross-country skiing, vigorous swimming, vigorous long distance bicycling”. The reliability was moderate ( $r=.51$ at $\mathrm{T} 1$ and $r=.49$ at T2).

\section{DATA ANALYSIS}

Data were analyzed using SPSS version 22. To test whether the relation between the dimensions of perfectionism (the independent variables, measured at T1) and MVPA, FVI, and sweet and salty snacks intake (the dependent variables, measured at T2) was moderated by gender, we performed moderator analyses using PROCESS (model 1) with 5000 bootstraps (Hayes, 2013). PROCESS allows the moderator regression analysis to be conducted, accounting for the covariates (the index of respective behavior at $\mathrm{T} 1$ ). Results of the analyses are presented using two types of coefficients. A regression coefficient for each parameter is provided (see Table 2 in section Results). Further, PROCESS estimates the conditional effect $(B)$ of the independent variable on the dependent variable (at respective values of moderator), accounting for respective covariates.

Missing data were imputed with multiple imputation, which is an effective way of treating data, even if up to $50 \%$ of data are missing (Pigott, 2001).

\section{RESULTS}

\section{PRELIMINARY ANALYSIS}

Attrition analysis indicated that completers and those who dropped out did not differ in gender, $\chi^{2}(1)=$ $=0.02, p=.596$, or perfectionism dimensions, all $F s<1.86$, all $p s>.173$, but older adolescents were 
more likely to not participate at $\mathrm{T} 2, F(1,843)=45.68$, $p<.001$ (dropouts: $M=16.48, S D=0.58$; completers: $M=16.11, S D=0.96)$.

The healthy behaviors remained stable over time. Repeated measures analysis of variance indicated that there was no change from $\mathrm{T} 1$ to $\mathrm{T} 2$ in the intake of sweet and salty snacks, $F(1,843)=1.26, p=.262$, FVI, $F(1,843)=3.58, p=.059$, or MVPA, $F(1,843)=3.16$, $p=.076$.

Correlation analysis showed that two types of perfectionism (T1) were associated with healthy behaviors at T2. In particular, higher levels of Perfectionism - Personal Standards were related to more frequent participation in physical activity (T2), higher FVI (T2) and lower intake of sweet and salty snacks (T2) (see Table 1). Similar associations were found for Perfectionism - Organization (T1). The remaining dimensions of perfectionism were not related to adolescents' healthy behaviors (Table 1), except for associations between higher Perfectionism-Parental Criticism and more frequent snacking (Time 2).

Participants with normal body weight and those with overweight/obesity did not differ in perfectionism indices, MVPA at T1 or T2, sweet and salty snack intake at T1 and T2, or FVI at T1 and T2, all $F \mathrm{~s}<1.09$, all $p s>.267$. Age was unrelated to the study variables, all $r s<.06$, all $p s>.051$. Finally, we found no differences between the three regions of data collection in terms of age, gender, BMI, perfectionism or healthy behaviors, all $F \mathrm{~s}<1.02$, all $p s>.250$. As the potential confounders were unrelated to the study variables, further analyses were conducted without controlling for age, region of data collection, or BMI.

An inspection of the effects of gender indicated that boys engaged in MVPA (T2) more frequently, $F(1,843)=38.12, p<.001, \eta^{2}=.04$ (boys: $M=3.12$, $S D=1.63$; girls: $M=2.45, S D=1.44)$. However, there were no gender differences in intake of sweet and salty snacks (T2), $F(1,843)=3.15, p=.076, \eta^{2}=.004$ (boys: $M=2.17, S D=0.84$; girls: $M=2.07, S D=0.78$ ) or in fruit and vegetable intake (T2), $F(1,843)=0.32$, $p=.315, \eta^{2}<.01$ (boys: $M=2.54, S D=0.94$; girls: $M=2.58, S D=0.98)$. There were no gender differences in dimensions of perfectionism, all $F \mathrm{~s}<1.93$, all ps > .165.

\section{EFFECTS OF PERFECTIONISM ON HEALTHY BEHAVIORS MODERATED BY GENDER}

Results of the moderation analysis for three indices of health behaviors (MVPA, FVI, and sweet and salty snacks intake) measured at $\mathrm{T} 2$ are presented in Table 1. These analyses tested our hypotheses, assuming that the effects of perfectionism may be moderated by participants' gender.

Fruit and vegetable intake was explained by the interaction of Gender x Perfectionism - Organization
$\left(\Delta r^{2}=.005, p=.040\right)$ and the interaction of Gender $\mathrm{x}$ Perfectionism - Personal Standards $\left(\Delta r^{2}=.004\right.$, $p=.043)$. For both interactions, the analyses of conditional effects showed significant associations among girls, with stronger Organization and Personal Standards at T1 being related to higher FVI (T2), after controlling for FVI at T1 (Table 2). Respective associations were negligible among boys. There were no significant interaction effects for other types of perfectionism and gender.

Sweet and salty snack intake was also explained by the interaction of Gender $x$ Perfectionism - Organization $\left(\Delta r^{2}=.004, p=.045\right)$ and the interaction of Gender x Perfectionism - Personal Standards $\left(\Delta r^{2}=.005, p=.036\right)$. For both interactions, the analyses of conditional effects showed significant associations among girls, with stronger Organization and Personal Standards at T1 being related to lower sweet and salty snack intake (T2), after controlling for baseline intake of sweet and salty snacks (Table 2). These associations were non-significant among boys. As in analyses conducted for FVI, no significant interaction effects for other types of perfectionism and gender were found for sweet and salty snack consumption.

The final set of analyses showed that moderate and vigorous physical activity levels at T2 were also explained by the interaction of Gender $\mathrm{x}$ Perfectionism - Organization $\left(\Delta r^{2}=.004, p=.039\right)$ and the interaction of Gender x Perfectionism - Personal Standards $\left(\Delta r^{2}=.006, p=.009\right)$. For both interactions, the analyses of conditional effects showed significant associations among boys, with stronger Organization and Personal Standards at T1 being associated with more frequent moderate and vigorous physical activity (T2), after controlling for baseline levels of physical activity (Table 2). These associations were non-significant among girls. Again, no significant interaction effects for other types of perfectionism and gender were observed.

\section{DISCUSSION}

The present study provides novel evidence for the role of functional perfectionism in health behavior change processes. In particular, the assessed dimensions of functional perfectionism (Personal Standards and Organization) predicted higher FVI, lower sweet and salty snack intake, and more frequent performance of physical activity at 12-month follow-up. The associations were moderated by gender: the functional perfectionism - healthy diet association was significant only among girls, whereas the functional perfectionism - physical activity relationship was significant only among boys.

The findings indicating positive associations between functional perfectionism and healthy behaviors are in line with previous research indicating 
Aleksandra Luszczynska, Karolina Zarychta, Karolina Horodyska, Natalia Liszewska, Anna Gancarczyk, Katarzyna Czekierda

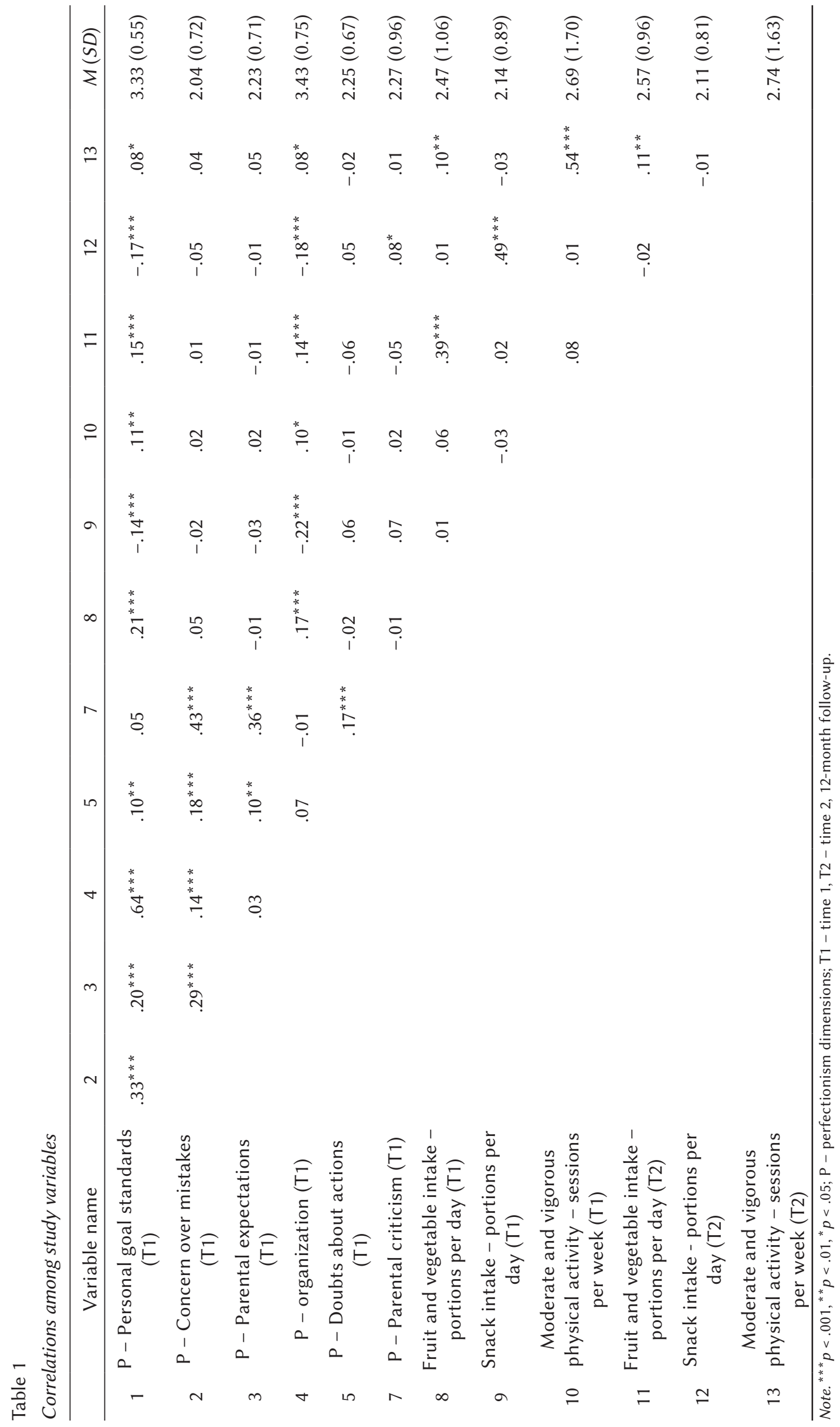




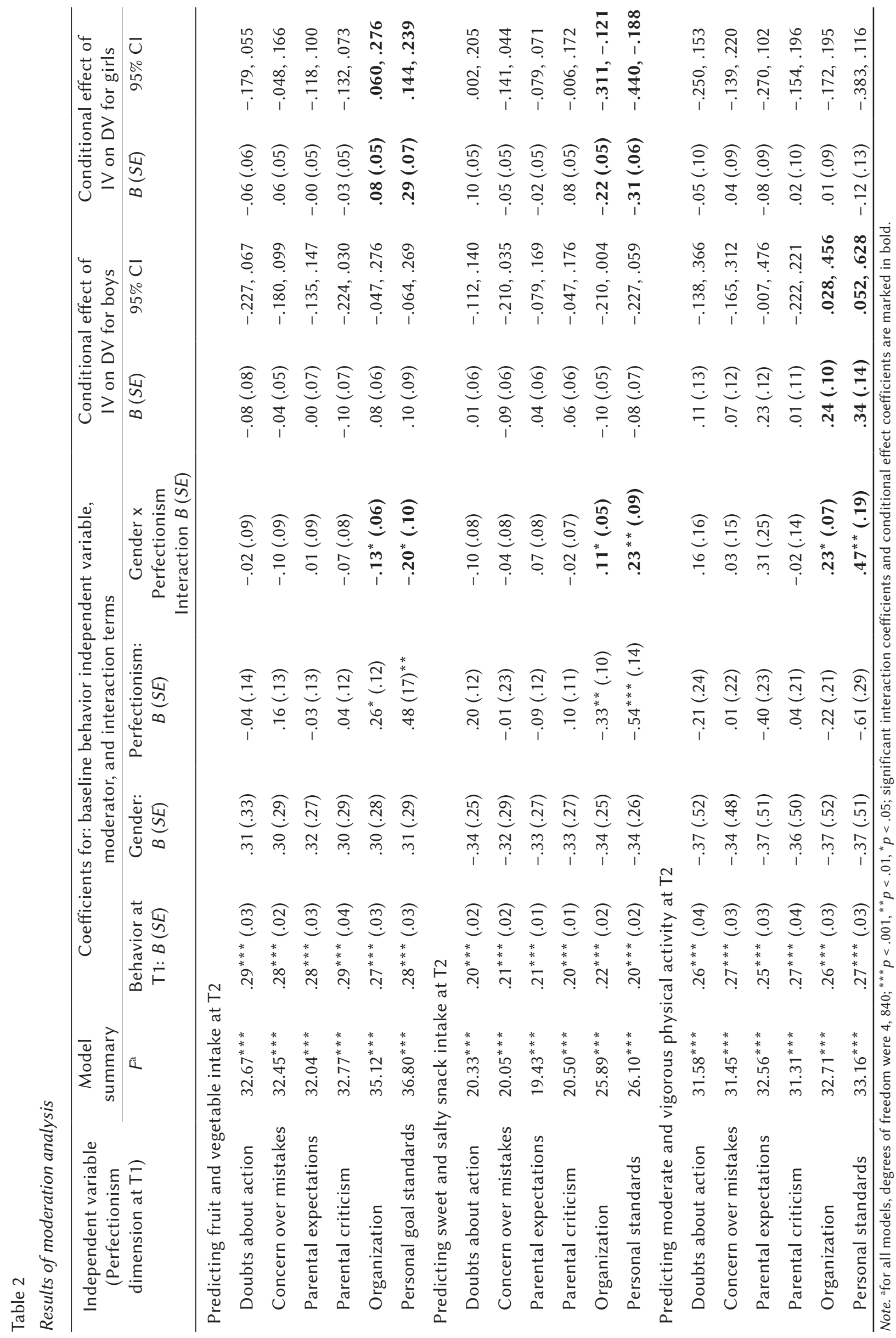


positive effects of functional perfectionism on functioning and adaptations in various domains, such as success orientation (Frost \& Henderson, 1991), goal commitment (Flett et al., 1995), goal attainment (Gaudreau \& Antl, 2008), or performance in sport (Gotwals et al., 2012). Beyond existing evidence focusing on domain-specific perfectionism, the present study showed that functional global perfectionism predicts three distinct healthy behaviors. Therefore, the results support the notion of conceptualizing perfectionism as a global personality trait, which may help to explain an individual's action across domains. These findings have implications for psychological practice. Adolescents with lower levels of global functional perfectionism may be in need of psychological intervention promoting healthy behavior change, as they may lack some personal resources facilitating behavior change.

So far, the investigation of associations between perfectionism and eating behaviors has been dominated by studies on symptoms of eating disorders (Franco-Paredes et al., 2005). Importantly, these analyses are predominantly conducted applying cross-sectional design and with a focus on the role of dysfunctional perfectionism. The present study provides evidence for the potential beneficial and adaptive role of functional perfectionism predicting healthy eating behaviors on long-term follow-ups, even after controlling for the baseline nutrition behavior. Future research may address the synergistic effects of both functional and dysfunctional perfectionism on both healthy eating and eating disorder symptoms.

Functional global perfectionism may promote healthy behaviors through various underlying mechanisms. It may be expected that individuals with higher levels of this trait may form stronger or more ambitious behavioral intentions or more frequently engage in forming action or coping plans. Forming behavioral intentions and plans is among the best proximal predictors of the uptake and maintenance of healthy behaviors (Hagger \& Luszczynska, 2014). Overall, personality variables form key personal resources prompting individuals to form intentions and plans (Hagger \& Luszczynska, 2014). Future research needs to investigate the mediating mechanisms that may help to disentangle underlying processes which explain the associations between global functional perfectionism and healthy behaviors.

The moderating effects of gender, discovered in the present study, are in line with earlier observations that critical self-evaluations (e.g., of own competences) are predictive of adolescents' physical activity but only among boys (Luszczynska \& Abraham, 2012). Further, previous investigations showed that gender moderates the associations between dysfunctional perfectionism and symptoms of eating disorders, with stronger associations found for wom- en (Shanmugam \& Davies, 2015). Our findings add to the existing evidence and indicate that the association between functional perfectionism and healthy nutrition behaviors is more pronounced among women. Thus, besides mere differences in average levels of functional perfectionism (Haase et al., 2013), the present study shows that the role of functional perfectionism may differ for men and women.

The present study has some limitations. The ongoing discussion on the role of global (measured as a general construct) and behavior-specific perfectionism (measured with reference to specific behaviors, such as MVPA; cf. Gotwals et al., 2012; Stoeber, 1998) indicates that the effects of global and behavior-specific perfectionism should be evaluated in one study in order to clarify their distinct effects. Future research should test whether global perfectionism explains the variance of behavioral outcomes over and above behavior-specific perfectionism. Our investigation did not test for the potential underlying mechanisms that may mediate the relationship between perfectionism and healthy behaviors, such as well-established predictors of healthy behaviors (e.g., intention, planning or self-efficacy, cf. Schwarzer et al., 2007; Szczepanska, Scholz, Liszewska, \& Luszczynska, 2013). Further, functional perfectionism is one of the personality resource variables which have a direct or indirect effect on healthy behaviors; effects of other personality variables, such as impulsivity, are better established (cf. Hagger \& Luszczynska, 2014). Consequently, future research needs to test for moderating and mediating mechanisms which may explain how and why perfectionism affects healthy behaviors.

\section{CONCLUSIONS}

In sum, our study offered an insight into associations between functional perfectionism and three health behaviors. The global index of functional perfectionism was associated with healthier diet (higher FVI and lower consumption of sweet and salty snacks) among adolescent girls, and it was associated with more frequent performance of physical activity among adolescent boys. Although the observed effects were small, the associations were established for behaviors measured at 12-month follow-ups, after controlling for the baseline measurement of respective behaviors.

The preparation of this paper was supported by grant NN 106012240 from the National Science Center.

\section{References}

Arata, A., Battini, V., Chiorri, C., \& Masini, B. (2010). An exploratory survey of eating behaviour pat- 
terns in adolescent students. Eating and Weight Disorders, 15, 200-207. DOI: 10.1007/BF03325301

De Onis, M., Onyango, A. W., Borghi, E., Siyam, A., Nishida C., \& Siekmann, J. (2007). Development of a WHO growth reference for school-aged children and adolescents. Bulletin World Health Organization, 85, 660-667. DOI: 10.2471/BLT.07.043497

Dombrowski, S. U., Sniehotta, F. F., Avenell, A., Johnston, M., MacLennan, G., \& Araujo-Soares, V. (2012). Identifying active ingredients in complex behavioural interventions for obese adults with obesity-related co-morbidities or additional risk factors for co-morbidities: a systematic review. Health Psychology Review, 6, 7-32. DOI: 10.1080/17437199.2010.513298

Flett, G. L., Sawatzky, D. L., \& Hewitt, P. L. (1995). Dimensions of perfectionism and goal commitment: A further comparison of two perfectionism measures. Journal of Psychopathology and Behavioral Assessment, 17, 111-124. DOI: 10.1007/BF02229013

Franco-Paredes, K., Mancilla-Diaz, J. M., VazquezArevalo, R., Lopez-Aguilar, X., \& Alvarez-Rayon, G. (2005). Perfectionism and eating disorders: a review of the literature. European Eating Disorders Review, 13, 61-70. DOI: 10.1002/erv.605

Frost, R. O., \& Henderson, K. J. (1991). Perfectionism and reactions to athletic competition. Journal of Sport and Exercise Psychology, 13, 323-335.

Frost, R. O., Marten, P., Lahart, C., \& Rosenblate, R. (1990). The dimensions of perfectionism. Cognitive Therapy and Research, 14, 449-468. DOI: 10.1007/ BF01172967

Gaudreay, P., \& Antl, S. (2008). Athletes' broad dimensions of dispositional perfectionism: examining changes in life satisfaction and the mediating role of sport-related motivation and coping. Journal of Sport and Exercise Psychology, 30, 356-382.

Godin, G., \& Shephard, R. J. (1985). A simple method to assess exercise behavior in the community. $\mathrm{Ca}$ nadian Journal of Applied Sport Sciences, 10, 141-146.

Gotwals, J. K., Stoeber, J., Dunn, J. G. H., \& Stoll, O. (2012). Are perfectionistic strivings in sport adaptive? A systematic review of confirmatory, contradictory, and mixed evidence. Canadian Psychology, 53, 263-279. DOI: 10.1037/a0030288

Haase, A. M., Prapavessis, H., \& Owens, R. G. (2013). Domain-specificity in perfectionism: variations across domains of life. Personality and Individual Differences, 55, 711-715. DOI: 10.1016/j. paid.2013.05.025

Hagger, M. S., \& Luszczynska, A. (2014). Implementation intention and action planning interventions in health contexts: State of the research and proposals for the way forward. Applied Psychology: Health and Well-Being, 6, 1-47. DOI: 10.1111/ aphw.12017

Hallal, P. C., Victora, C. G., Azevedo, M. R., \& Wells, J. C. K. (2006). Adolescent physical activ- ity and health: A systematic review. Sports Medicine, 36, 1019-1030.

Hayes, A. F. (2013). An introduction to mediation, moderation, and conditional process analysis: A regression-based approach. New York: Guilford Press.

Lally, P., Bartle, N., \& Wardle, J. (2011). Social norms and diet in adolescents. Appetite, 57, 323-327. DOI: 10.1016/j.appet.2011.07.015

Longbottom, J. L., Grove, J. R., \& Dimmock, J. A. (2010). An examination of perfectionism traits and physical activity motivation. Psychology of Sport \& Exercise, 11, 574-581. DOI: 10.1016/j. psychsport.2010.06.007

Luszczynska, A., \& Abraham, C. (2012). Reciprocal relationships between three aspects of physical self-concept, vigorous physical activity, and lung function: A longitudinal study among late adolescents. Psychology of Sport \& Exercise, 13, 640-648. DOI: 10.1016/j.psychsport.2012.04.003

Luszczynska, A., de Wit, J. B. F., de Vet, E., Januszewicz, A., Liszewska, N., Johnson, F., Pratt, M., Gaspar, T., de Matos M. G., \& Stok, F. M. (2013). At-home environment, out-of-home environment, snacks and sweetened beverages intake in preadolescence, early and mid-adolescence: the interplay between environment and self-regulation. Journal of Youth and Adolescence, 42, 1873-1883. DOI: 10.1007/s10964-013-9908-6

Luszczynska, A., Scholz, U., \& Schwarzer, R. (2005). The general self-efficacy scale: Multicultural validation studies. Journal of Psychology, 139, 439-457.

Nelson, M. C., Neumark-Sztainer, D., Hannan, P. J., Sirard, J. R., \& Story, M. (2006). Longitudinal and secular trends in physical activity and sedentary behavior during adolescence. Pediatrics, 118, 16271634. DOI: 10.1542/peds.2006-0926

Pate, R. R., Freedson, P. S., Sallis, J. F., Taylor, W., Sirard, J., \& Trost, S. (2002). Compliance with physical activity guidelines: prevalence in a population of children and youth. Annals of Epidemiology, 12, 303-308. DOI: 10.1016/S1047-2797(01)00263-0

Piernas, C., \& Popkin, B. M. (2010). Trends in snacking among U.S. children. Health Affairs, 29, 398404. DOI: $10.1377 /$ hlthaff.2009.0666

Pigott, T. D. (2001). A review of methods for missing data. Educational Research and Evaluation, 7, 353383.

Reilly, J. J., \& Kelly, J. (2011). Long-term impact of overweight and obesity in childhood and adolescence on morbidity and premature mortality in adulthood: systematic review. International Journal of Obesity, 35, 891-898. DOI: 10.1038/ ijo.2010.222

Schwarzer, R., Shuez, B., Ziegelmann, J. P., Lippke, S., Luszczynska, A., \& Scholz, U. (2007). Adoption and maintenance of four health behaviors: Theory-guided longitudinal studies on dental flossing, seat belt use, dietary behavior, and physical ac- 
tivity. Annals of Behavioral Medicine, 33, 156-166. DOI: 10.1007/BF02879897

Shanmugam, V., \& Davies, B. (2015). Clinical perfectionism and eating psychopathology in athletes: The role of gender. Personality \& Individual Differences, 74, 99-105. DOI: 10.1016/j.paid.2014.09.047

Sherry, S. B., Hewitt, P. L., Sherry, D. L., Flett, G., \& Graham, A. R. (2010). Perfectionism dimensions and research productivity in psychology professors: Implications for understanding the (mal) adaptiveness of perfectionism. Canadian Journal of Behavioural Science, 42, 273-283. DOI: 10.1037/ a0020466

Stoeber, J. (1998). The Frost Multidimensional Perfectionism Scale: More perfect with four (instead of six) dimensions. Personality and Individual Differences, 24, 481-491. DOI: http://dx.doi.org/10.1016/ S0191-8869(97)00232-8

Stoeber, J., Uphill, M. A., \& Hotham, S. (2009). Predicting race performance in triathlon: The role of perfectionism, achievement goals, and personal goal setting. Journal of Sport \& Exercise Psychology, 31, 211-224.

Stotland, S. C., \& Larocque, M. (2005). Early treatment response as a predictor of ongoing weight loss in obesity treatment. British Journal of Health Psychology, 10, 601-614. DOI: 10.1348/ 135910705X43750

Szczepanska, K. W., Scholz, U., Liszewska, N., \& Luszczynska, A. (2013). Social and cognitive predictors of fruit and vegetable intake among adolescents: The context of changes in body weight. Journal of Health Psychology, 18, 667-679. DOI: 10.1177/1359105312437434

Warburton, D. E. R., Nicol, C. W., \& Bredin, S. S. (2006). Health benefits of physical activity: the evidence. Canadian Medical Association Journal, 174, 801-809. DOI: 10.1503/cmaj.051351

World Health Organization. (2004). Global Strategy on Diet, Physical Activity and Health. Retrieved from http://www.who.int/dietphysicalactivity/strategy/ en/

World Health Organization. (2007). Application tools. WHO AnthroPlus software. Retrieved from http:// www.who.int/growthref/tools/en/ 